\title{
Scientometric assessment of research publications from fisheries institutes under Indian Council of Agricultural Research (ICAR) during 2009-2018
}

\author{
DASARI BHOOMAIAH ${ }^{1,2}$, P. KRISHNAN ${ }^{3}$, G. KANTHARAJAN ${ }^{4}$, K. V. RAJENDRAN ${ }^{2}$, \\ A. G. PONNIAH ${ }^{3}$ AND CH. SRINIVASA RAO ${ }^{3}$ \\ ${ }^{1}$ Ponnaiyah Ramajayam Institute of Science and Technology (Deemed University), Vallam, Thanjavur - 613403 \\ Tamil Nadu, India \\ ${ }^{2}$ ICAR-Central Institute of Fisheries Education, Versova, Mumbai - 400 061, Maharashtra, India \\ ${ }^{3}$ ICAR-National Academy of Agricultural Research Management, Hyderabad - 500 030, Telangana, India \\ ${ }^{4}$ ICAR-National Bureau of Fish Genetic Resources, Lucknow - 226 002, Uttar Pradesh, India \\ e-mail:krishnanars@yahoo.com
}

\begin{abstract}
The national fisheries research in India is spearheaded by domain-specific fisheries research institutions under the aegis of the Indian Council of Agricultural Research (ICAR), New Delhi. The current study was undertaken to assess the temporal trends in research publications during the period 2009-2018, from eight fisheries research institutes under ICAR using 'SciVal', a web-based scientometric tool of Elsevier for measuring research performance. The data on various research metrics, such as the number of publications, their citations, field-weighted research impacts, number of publications in top journals, subject area categories and key phrases used in research outputs were extracted from the application. The assessment revealed that a total of 3263 papers were published by the fisheries research institutes under ICAR during the study period, which received 24,253 citations in total. The number of publications from the ICAR fisheries research institutes and their quality showed a steady increase over the years. The foremost journal for publishing Indian fisheries research outputs during the assessment period was the Indian Journal of Fisheries (408 papers; 12.5\%) published by ICAR, New Delhi. The research focus of these institutes was found to be more towards the widely cultivated species, i.e., Penaeus (=Litopenaeus) vannamei and Pangasionodon hypophthalmus. The present study highlights the research areas with significant momentum and scope for future funding; provides insights on the research trends and necessary leads to prioritise research among the national fisheries research institutes under ICAR.
\end{abstract}

Keywords: Citations, Fisheries research, ICAR, India, SciVal, Scientometrics

\section{Introduction}

Fisheries and aquaculture form a subset of life sciences and research covering various aspects of these domains have been underway in different national and state; public and private; research and academic organisations. State agricultural universities with fisheries faculty and traditional universities have also contributed to the advancement of knowledge in fisheries as reported by Jayashree and Arunachalam (2000). The systematic fisheries research in India started in the 1940s through the Union Government initiative to establish the country's first dedicated fisheries research centre of Central Marine Fisheries Research Station (now known as the ICARCentral Marine Fisheries Research Institute) on 03 February 1947 (Silas, 2003). Since then, the country had seen a progressive transformation in fisheries research with the establishment of more fisheries institutes, under the Indian Council of Agricultural Research (ICAR), New Delhi, each specifically focusing on a particular research and development (R\&D) domain related to freshwater, brackishwater and marine capture and culture fisheries, which included aspects on fish harvest and postharvest technology, genetic resources documentation and management, cold-water fisheries and human resource development (Ayyappan and Diwan, 2006). As of now, eight fisheries research institutes with specific subject focus and pan-India scope, are operating under the aegis of ICAR. Apart from these institutes, location-specific fisheries research is also underway in the ICAR research complexes based in Andamans (ICAR-Central Island Agricultural Research Institute, Port Blair); Goa (ICARCentral Coastal Agricultural Research Institute, Goa); Meghalaya (ICAR Research Complex for the North-east Hill Region, Umium) and Bihar (ICAR Research Complex for Eastern Region, Patna). A few fisheries scientists also serve in ICAR crop/animal science institutes and undertake research on fisheries as a component of integrated farming system. 
Periodical assessment of the trend in research focus and performance of any organisation is necessary to evaluate the continued relevance to the present-day requirements and the nature of scope in meeting the future needs both nationally and globally. Further, in recent times, the need for evaluation of the research programmes of different organisations is growing because of demands for greater accountability and effectiveness (OECD, n.d.). Scientometrics is considered a reliable tool for the research performance evaluation and plays a crucial role in decision making for periodical refinement and reorientation of national research policies in tune with the global standards and also for appropriate funding for infrastructure and manpower requirement. It analyses the data which are relevant to the essence of scientific work of individual researcher, research group, organisation and at country levels (Bornmann and Leydesdorff, 2014). Several tools are used for the scientometric assessment like Web of Science (WoS), InCites, Scopus, SciVal, Google Scholar and Publish or Perish (Smith, 2017; Brennan, 2018).

SciVal, which uses advanced citation data analyses, is a potential tool to assess the productivity of faculties/ institutes and their existing collaborations through analyses of publications (Dresbeck, 2015; Waltman, 2016). It enables us to evaluate the research performance relating to a variety of perspectives based on reliable evidence gleaned from over 50 million publication records from more than 22,000 journals of 5,000+ publishers worldwide (SciVal, 2020). Many scientometric studies have used the SciVal tool to assess the research performance of universities and other organisations (Khor and Yu, 2016; Rajan et al., 2018). Earlier scientometric studies, applied in the Indian fisheries science field covering the overall subjects, selected research topics viz., fish stock assessment, seaweeds and white spot syndrome virus (WSSV) and significantly from the journal Aquaculture and the Journal of Marine Biological Association of India (Jayashree and Arunachalam, 2000; Arunachalam and Jeyashree, 2001; Vivekanandan et al., 2009; Kumaresan et al., 2013, 2014, 2015; Chaman et al., 2016; Singh et al., 2019; Bhoomaiah et al., 2020). Analysis of research outputs of the Indian fisheries sector during 1992-2016, using the WoS database, showed the significant contribution of ICAR fisheries institutes (Vinitha et al., 2018) in advancing knowledge in various facets of the field.

In the present study, an effort has been made to undertake a scientometric overview of eight ICAR fisheries research institutes, which have significant role in spearheading the national fisheries development, based on the research papers published by them during the period from 2009 to 2018, using SciVal. This bibliometric tool helps to assess the research performance, its quality and the impact of research outputs, especially in social and economic domains by analysing the publication data at institutional and collaborative levels. The results would aid in understanding the research focus and contribution of ICAR fisheries institutes and would help to provide insights and direct the way forward to sustainable fisheries development in India.

\section{Materials and methods}

Publication and citation metrics, journal metrics and collaboration metrics are used for assessing research performance. The present study used Elsevier's bibliometric tool, SciVal (representing Science Value) (https://www.scival.com) as the main data source to assess the research performance of Indian fisheries research institutes viz., ICAR-Central Marine Fisheries Research Institute (ICAR-CMFRI), Kochi; ICAR-Central Inland Fisheries Research Institute (ICAR-CIFRI), Barrackpore; ICAR-Central Institute of Fisheries Technology (ICARCIFT), Kochi; ICAR-Central Institute of Fisheries Education (ICAR-CIFE), Mumbai; ICAR-National Bureau of Fish Genetic Resources (NBFGR), Lucknow; ICAR-Central Institute of Freshwater Aquaculture (ICAR-CIFA), Bhubaneshwar; ICAR-Central Institute of Brackishwater Aquaculture (ICAR-CIBA), Chennai and ICAR-Directorate of Coldwater Fisheries Research (ICAR-DCFR), Bhimtal functioning under the ICAR, New Delhi. All the above fisheries institutes have a specialised research focus viz., Marine fisheries, Marculture, Inland fisheries, Cold water fisheries, Freshwater aquaculture, Brackishwater aquaculture, Fish genetic resources or Harvest and post-harvest technology, except ICARCIFE which, being a Deemed University under ICAR, undertakes research on all aspects of fisheries, cutting across disciplines. The present study does not include fisheries research publications from research complexes under ICAR and different academic institutes across the country. The scientific and technical manpower status of these institutes were extracted from their respective Annual Reports of the year 2014 (Fig. 1). In case of ICARCIFE, the masters and $\mathrm{Ph}$. D. students also contribute to the research publications of the institute, but their number is not included as part of the scientific manpower to estimate research productivity.

The SciVal offers quick and easy access to the details of the research performance of more than 19,100 research institutions and their associated researchers worldwide. Initially, the ICAR fisheries institutes were selected one by one in the entity panel and grouped as ICAR-Indian fisheries institutes in the SciVal tool. The scholarly research outputs published by the scientists of the respective institutes during 2009 to 2018 were extracted from SciVal in May 2020. The data on various research metrics, such as Scholarly Output, Citation Count, Citations per 


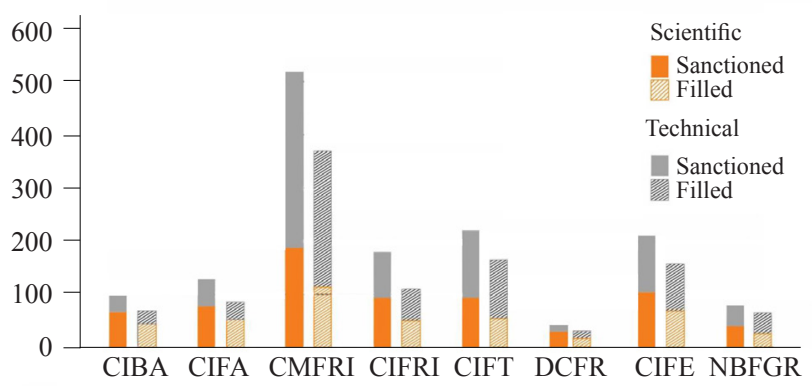

Fig. 1. Scientific and technical manpower status (2014) of Fisheries Research Institutes under ICAR

Publication (CPP), Field-Weighted Citation Impact (FWCI), papers in Top Citation and Journal Percentiles were extracted for ICAR fisheries institutes as an entity. FWCI compares the article citation count of a particular institute to the average citation count of similar articles published elsewhere in the same field and time frame.

Besides, details on the top subject area category, top journals and most widely used key-phrases in publications were also extracted from the database. The SciVal based 'Topic Prominence (TP) analysis' of research papers, which is based on its (1) citation count and (2) Scopus views count in year ' $n$ ' to papers published in $n$ and $n-1$ and (3) average cite score for the year ' $n$ ', were performed for ICAR fisheries institutes. A 'topic' is a collection of articles focused on a common intellectual research problem, clustered together based upon a direct citation analysis. TP analyses aid in finding topics in which the research momentum of an institute is high and the areas which are likely to be well-funded in the future (Elsevier, 2020b).

In key phrase-based assessment, the 'relevance value' of each key phrase range from 0 to 1 , where the highest value, i.e. 1 is assigned to the most frequently occurring keyword. The remaining key phrases were given a value based on their relative frequency, which is also projected by the size of the key phrases in the word cloud figure (SciVal, 2020).

\section{Results and discussion}

Pattern of publications and citations from ICAR Fisheries Research Institutes

The summary results of the 'SciVal' based scientometric assessment on publications from national fisheries research laboratories under ICAR are provided in Table 1 . The study revealed that a total of 3263 papers were published by ICAR fisheries institutes during 2009-18, which received 24,253 citations. A steady increase in the publication count was observed from 2009 (197 papers) to 2018 (462 papers). Scientometric study on Indian fisheries research using 6 different databases (Jayashree and Arunachalam, 2000) reported a total of 2454 publications from all Indian research and academic institutes during 1994-1999. A recent scientometric assessment based on 'Scopus' database using search keywords 'Fisheries', 'Fishery' and 'Aquaculture' reported 10,999 papers published during 2006-2017 (Singh et al., 2019). The significant increase in the number of publications may be attributed to the evolving Human Resource (HR) policies, the introduction of objective and quantitative performance metrics for career advancement of scientists (effective from 2009), enhanced sensitisation on research publications and improved inter-institutional collaboration due to information technology advancements (ASRB, 2009; Bhoomaiah et al., 2020).

In contradiction to this, Vinitha et al. (2018) reported only 2639 publications having been included in the 'Web of Science' database for the search term 'Fisheries' in 'India (n)' geographical range during 1992-2016. The observed difference in the number of publications could be attributed to the journal coverage between the databases and variation in the search terms selected for the analysis. The present study has used the Scopus-based tool i.e. SciVal for the analysis. The highest number of citations per publication (12.3 CPP in 2013) reported during the initial period of assessment was mainly due to the extended record of time under consideration for those publications, which accounted for more citations over such a period. The research performance evaluation of organisations based on the citations of recent years' publications provides little

Table 1. Temporal trends in the cumulative research publications and pattern of citations from Fisheries Research Institutes under ICAR during 2009-2018

\begin{tabular}{llllllllllll}
\hline Metrics & 2009 & 2010 & 2011 & 2012 & 2013 & 2014 & 2015 & 2016 & 2017 & 2018 & Overall \\
\hline No. of papers & 197 & 206 & 247 & 336 & 314 & 354 & 304 & 383 & 460 & 462 & 3263 \\
Citations & 2424 & 2893 & 2617 & 3030 & 2866 & 3057 & 2017 & 2270 & 1860 & 1219 & 24253 \\
Citations per publication & 12.30 & 14.00 & 10.60 & 9.00 & 9.10 & 8.60 & 6.60 & 5.90 & 4.00 & 2.60 & 7.40 \\
Field-weighted citation impact & 0.39 & 0.53 & 0.49 & 0.46 & 0.49 & 0.54 & 0.53 & 0.64 & 0.62 & 0.67 & 0.56 \\
Outputs in top citation percentiles (Top 10\%) & 4.10 & 6.30 & 6.90 & 5.10 & 5.40 & 5.90 & 4.60 & 6.30 & 3.90 & 5.60 & 5.40 \\
$\begin{array}{l}\text { Publications in top journal percentiles (Top 10\% } \\
\text { by Cite score percentile) }\end{array}$ & 11.30 & 9.40 & 7.80 & 8.40 & 8.70 & 7.80 & 9.10 & 13.50 & 14.90 & 20.40 & 11.9
\end{tabular}


information and hence a window period of at least 3 years need to be considered for the citation-based assessments (Bornmann and Leydesdorff, 2014)

The lowest Field Weighted Citation Impact (FWCI) value (0.39) was derived for the publications during 2009 and the highest value of 0.67 was obtained for publications made in the year 2018. The SciVal based FWCI compares the number of citations received by the publications of a particular institute/year along with the average number of citations received by all the other similar publications indexed in the Scopus database. For instance, FWCI value 1 indicates that the publication's citation impact is the same as the other similar publications indexed in the Scopus database (Elsevier, 2020a; Purkayastha et al., 2019). The results lead us to infer that the citation impact of ICAR fisheries institutes has improved over the period ( 0.39 in 2009 to 0.67 in 2018) and there is a need to sustain this research focus to stand on par (i.e. FWCI $\geq 1$ ) with other similar papers published at the global arena.

Though the extent of research outputs of ICAR fisheries institutes published in the Top Citation Percentiles (top 10\%) group during the study period was observed to be low $(5.4 \%)$, the number of papers published in the top journal percentiles (top $10 \%$ by CiteScore Percentile) group was found to be on the increase, especially after 2016 , indicating an improvement in the quality of the research publications (Table 1).

\section{ICAR-Fisheries Institute-wise research output}

Among the fisheries institutes, the highest number of publications was made by ICAR-CMFRI (847 papers), followed by ICAR-CIFE ( 825 papers), ICAR-NBFGR (487 papers) and ICAR-CIFA (483 papers) (Table S1). The temporal trend in the number of publications from all the fisheries institutes showed a steady increase over the years (Fig. 2). While ICAR-CMFRI and ICAR-CIFE recorded a consistently increasing trend in the total number of publications since 2015, the rate of increase was much sharper in the former. The consistent increase in the number of scholarly outputs temporally in specific organisations could be attributed to the measures implemented to promote ease of doing research, in general and to facilitate development of knowledge products, in particular. ICAR-DCFR showed a gradually declining trend of publications in the corresponding period.

The ICAR fisheries research institutes were plotted in a decision matrix (Fig. 3) based on their cumulative scholarly output and citations during 2009-18 in order to understand their relative research output and influence, notwithstanding the differences among them in terms of their size (number of human resources and budget) and age. ICAR-CMFRI and ICAR-CIFE recorded higher publications and citations ( $>500$ publications and 3500 citations) compared to the other organisations. Previous scientometric studies performed on Indian fisheries research since 1992 also reported ICAR-CMFRI as the top institute in terms of scholarly output, which reflects its prominent contribution to the marine fisheries research, over the period (Jayashree and Arunachalam, 2000; Vivekanandan et al., 2009; Vinitha et al., 2018).

The Average Citations per Publication (ACPP) value was found to be higher for the publications of ICAR-CIFA, followed by ICAR-CIFT and ICAR-NBFGR (Fig. 3), which suggest that the research interest among the scientists in the areas of freshwater aquaculture, fishing technology and fish genetic resource assessment, which are the focus areas of the above institutes, respectively, are higher than that of natural resource management. In the present study, total citations include self-citations which ranged between $9.12 \%$ (DCFR) and $14.48 \%$ (NBFGR) of the total citations, with a mean value of $10.52 \pm 2.27 \%$. There are documented views for and against self-citations (Soares et al., 2015), which vary with the field of study (Neuroscience - 18\%; Psychology - 21\%; Biology - 12\%) (Aksnes, 2003; Hyland, 2003). While self-citations in zoological studies in general and taxonomic studies in particular can not necessarily be considered as fraudulent (Pinto et al., preprint), instances of researchers citing their earlier papers under irrelevant circumstances to establish their own scientific authority or to enhance their visibility have also been recognized (Lawani, 1982; Esfe et al., 2015).

The publications of ICAR-CIBA had the highest FWCI (0.73) (Fig. 3; Table S1), which indicates that these publications attracted $73 \%$ of average citations, of similar articles published in the same field and time frame globally (Purkayastha et al., 2019). The FWCI considers the differences in research behaviour across disciplines, hence it is considered as a better indicator than the raw citation count of an institute (UC, 2020; Elsevier, 2020a).

The research productivity (average publications per scientist) was found to be the highest for ICAR-NBFGR (17.39), followed by ICAR-CIFE (11.79) and ICARDCFR (10.47) (Fig. 4). Higher research productivity in these institutes could be attributed to measures taken to facilitate implementation of research projects and to develop knowledge products. It could also be related to the field of research of the respective institutes. ICARCIFE, being a deemed university, undertakes research under diverse areas and its research outputs also include publications made as part of students' research.

The SciVal-based data on the publications in top 10 percentile is widely used as an indicator to assess the quality of the research (Rajan et al., 2018). Publications in top journal, citation or views percentiles represent the number of publications of a selected entity that have 


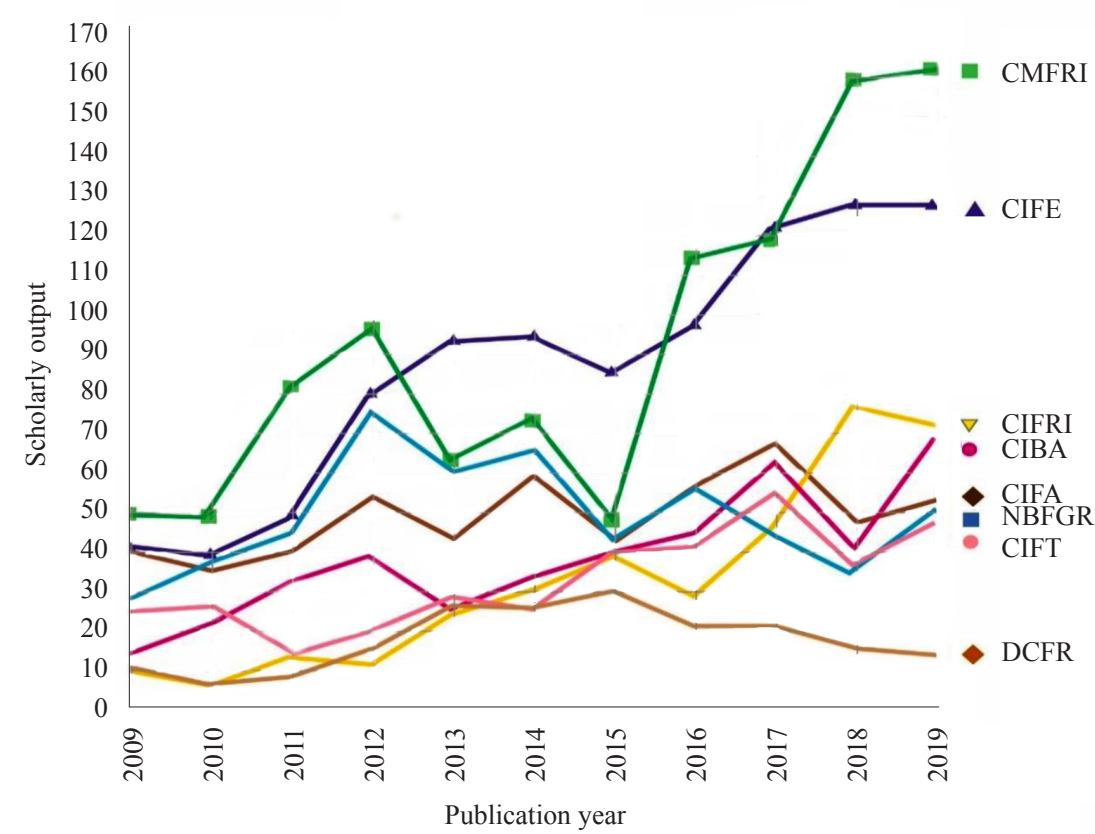

Fig. 2. Temporal trend in the number of research papers from Fisheries Research Institutes under ICAR during 2000-2019

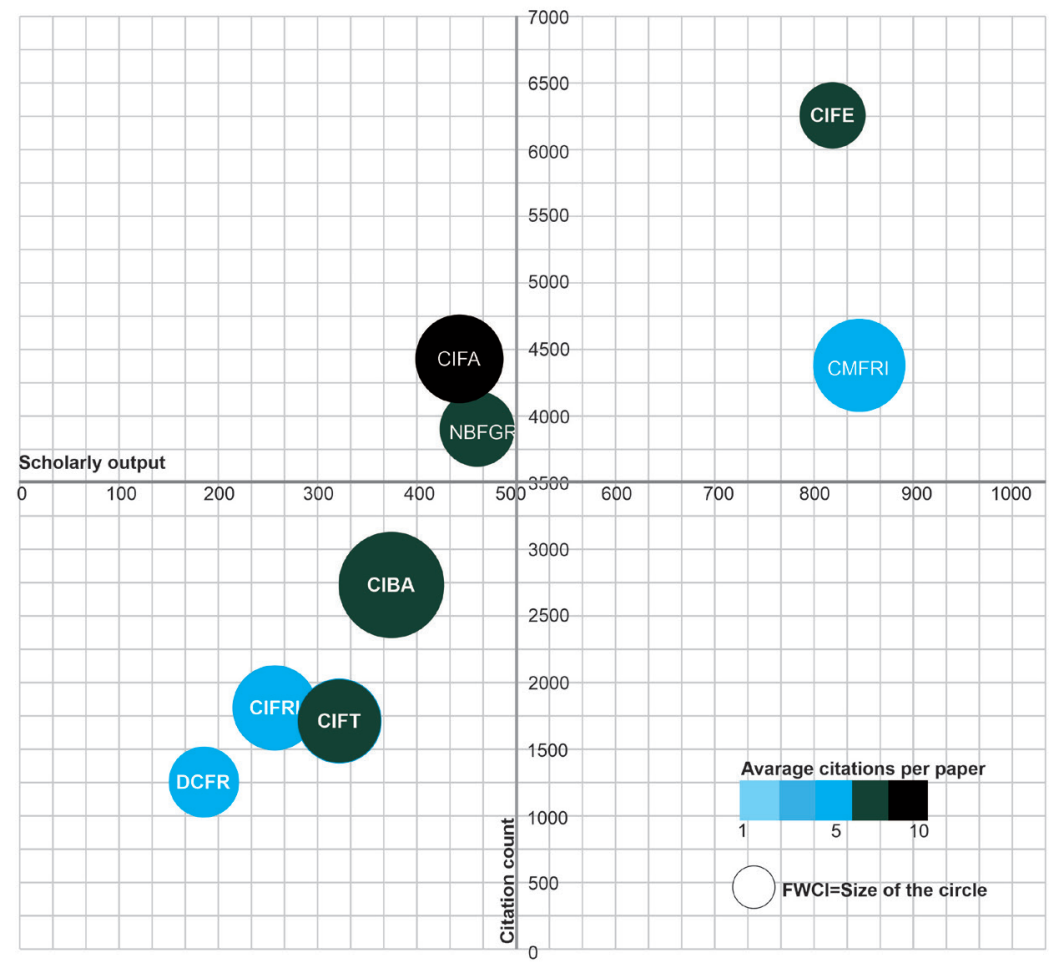

Fig. 3. Decision matrix showing the scholarly output of Fisheries Research Institutes under ICAR against their respective citations during 2009-2018

been published in the world's top journals or those which are highly cited or viewed, having reached a threshold, respectively. The proportion of publications in top journal and citation percentiles was the highest for ICAR-CIBA, while the outputs from ICAR-CIFT had the highest visibility as it topped among the institutes in terms of maximum outputs in top views percentiles (Fig. 5).

Subject area-wise publications

The subject area-wise scholarly output assessment was undertaken by adopting the Scopus journal 


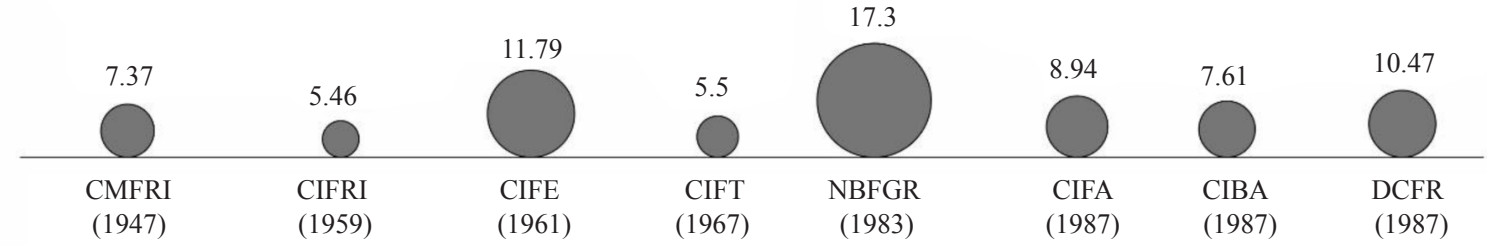

Fig. 4. Research productivity (research papers per scientist) of Fisheries Research Institutes under ICAR during 2009-2018. Year of establishment of the institute is provided in parenthesis

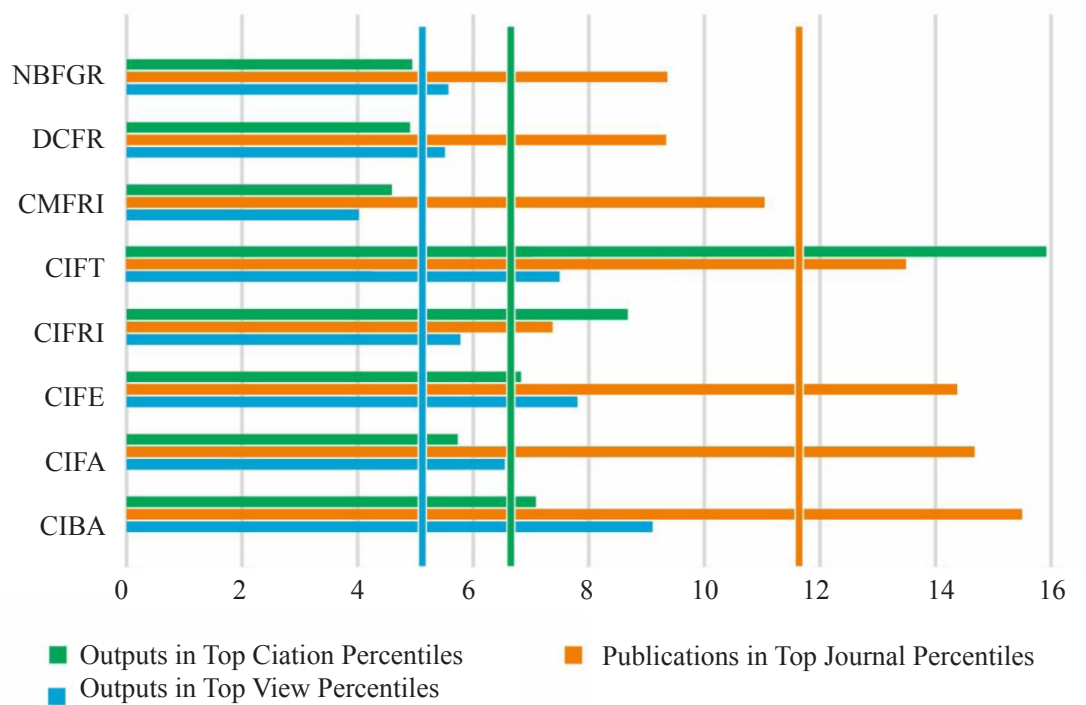

Fig. 5. Quality characteristics of research publications from individual ICAR Fisheries Research Institutes during 2009-2018 (vertical lines represent average value of IFRIs for respective parameters)

classification system i.e., All Science Journal Classification (ASJC), which indicated that the top 3 subject areas focused by ICAR fisheries institutes were 'Agricultural and Biological Sciences’ (2024 papers; ICAR-CMFRI topping the list with 599 papers); 'Biochemistry, Genetics and Molecular Biology’ (699 papers; ICAR-NBFGR accounting for 205 papers) and 'Environmental Science' (636 papers; with ICAR-CMFRI accounting for 125). The subject area, 'Earth and Planetary Sciences' (271 papers; ICAR-CMFRI - 154 papers) covering Oceanography, General Earth and Planetary Sciences, Atmospheric Sciences and Geology, showed very high percentage growth in the number of publications and authors (Table 2; Fig. 6) between 2009 and 2018. Detailed information on subject area-wise research publications (2009-18) showed that ICAR fisheries institutes undertake research on diverse fields and publish them in journals dedicated to different subject areas, viz., 'Chemical engineering', 'Earth sciences', 'Pharmacology, toxicology and pharmaceutics', 'Medicine' and 'Psychology'. The FWCI values for publications of the top 10 subject areas were found to range between 0.33 (Earth and Planetary Sciences) and 1.01 (Chemistry), indicating the reach of these publications compared to other subject areas. In the light of the diversification in research that is underway in the national fisheries research institutes and their increasing influence and visibility, it is pertinent to institutionalise capacity building programmes in inter-disciplinary areas.

The 'Topic Prominence analysis' depicted in a wheel (Fig. 7), as obtained from the SciVal platform, provides a measure of visibility, momentum and demand of a particular 'Topic' in a research subject area (Elsevier, 2020b; Klavans and Boyack, 2017). While 'topic prominence' can aid in recognising the research areas with potential to attract more funds, it does not necessarily represent the importance of research (Klavens and Boyack, 2017), which are driven by strategic goals and societal values of the organisations, as in case of national fisheries research institutes. The present study on ICAR fisheries institutes suggests that the topics under the subject area clusters 'Agricultural and Biological Science'; 'Biochemistry, Genetics and Molecular Biology"; "Environmental Sciences'; 'Immunology and Microbiology'; 'Social Sciences' and 'Chemistry/Chemical Engineering' could attract more funds in the upcoming years. The prominent topic clusters which have the highest percentile value $(>95 \%)$ are listed in Table S2. In particular, the topic clusters such as 'Photocatalysis, Photocatalysts, Solar Cells'; 
Table 2. Subject area-wise* research publications from different Fisheries Research Institutions under ICAR during 2009-18

\begin{tabular}{|c|c|c|c|c|c|c|c|}
\hline \multirow[b]{2}{*}{ Broad subject area (Number of sub-categories) } & \multicolumn{2}{|c|}{ Research publications } & \multicolumn{2}{|c|}{ Authors } & \multicolumn{2}{|c|}{ Citations } & \multirow{2}{*}{$\begin{array}{l}\text { Field-weighted } \\
\text { Citation Impact } \\
(\mathrm{FWCI})\end{array}$} \\
\hline & $\begin{array}{l}\text { No. of } \\
\text { papers }\end{array}$ & $\%$ Growth $^{* *}$ & $\begin{array}{l}\text { No. of } \\
\text { Authors }\end{array}$ & $\%$ Growth $^{* *}$ & Total & $\begin{array}{l}\text { Citations per } \\
\text { publication }\end{array}$ & \\
\hline Agricultural and Biological Sciences (12) & 2024 & 100.0 & 2155 & 132.5 & 15361 & 7.6 & 0.61 \\
\hline Biochemistry, Genetics and Molecular Biology (16) & 699 & 169.7 & 805 & 218.7 & 6840 & 9.8 & 0.61 \\
\hline Environmental Science (13) & 636 & 79.6 & 952 & 169.9 & 5311 & 8.4 & 0.59 \\
\hline Immunology and Microbiology (6) & 273 & 100.0 & 420 & 124.4 & 2684 & 9.8 & 0.64 \\
\hline Earth and Planetary Sciences (7) & 271 & 800.0 & 440 & 1153.8 & 1148 & 4.2 & 0.33 \\
\hline Veterinary (5) & 206 & 71.4 & 410 & 153.5 & 1083 & 5.3 & 0.58 \\
\hline Medicine (23) & 187 & 73.3 & 378 & 100.0 & 1960 & 10.5 & 0.67 \\
\hline Pharmacology, Toxicology and Pharmaceutics (5) & 129 & 42.9 & 235 & 46.2 & 1231 & 9.5 & 0.68 \\
\hline Chemical Engineering (9) & 121 & 140.0 & 277 & 92.9 & 1310 & 10.8 & 0.62 \\
\hline Engineering (11) & 120 & 157.1 & 251 & 369.2 & 718 & 6.0 & 0.66 \\
\hline Chemistry (7) & 116 & 300.0 & 199 & 238.5 & 1633 & 14.1 & 1.01 \\
\hline
\end{tabular}

"Subject categories as per SciVal (Scopus)

*"between 2009 and 2018

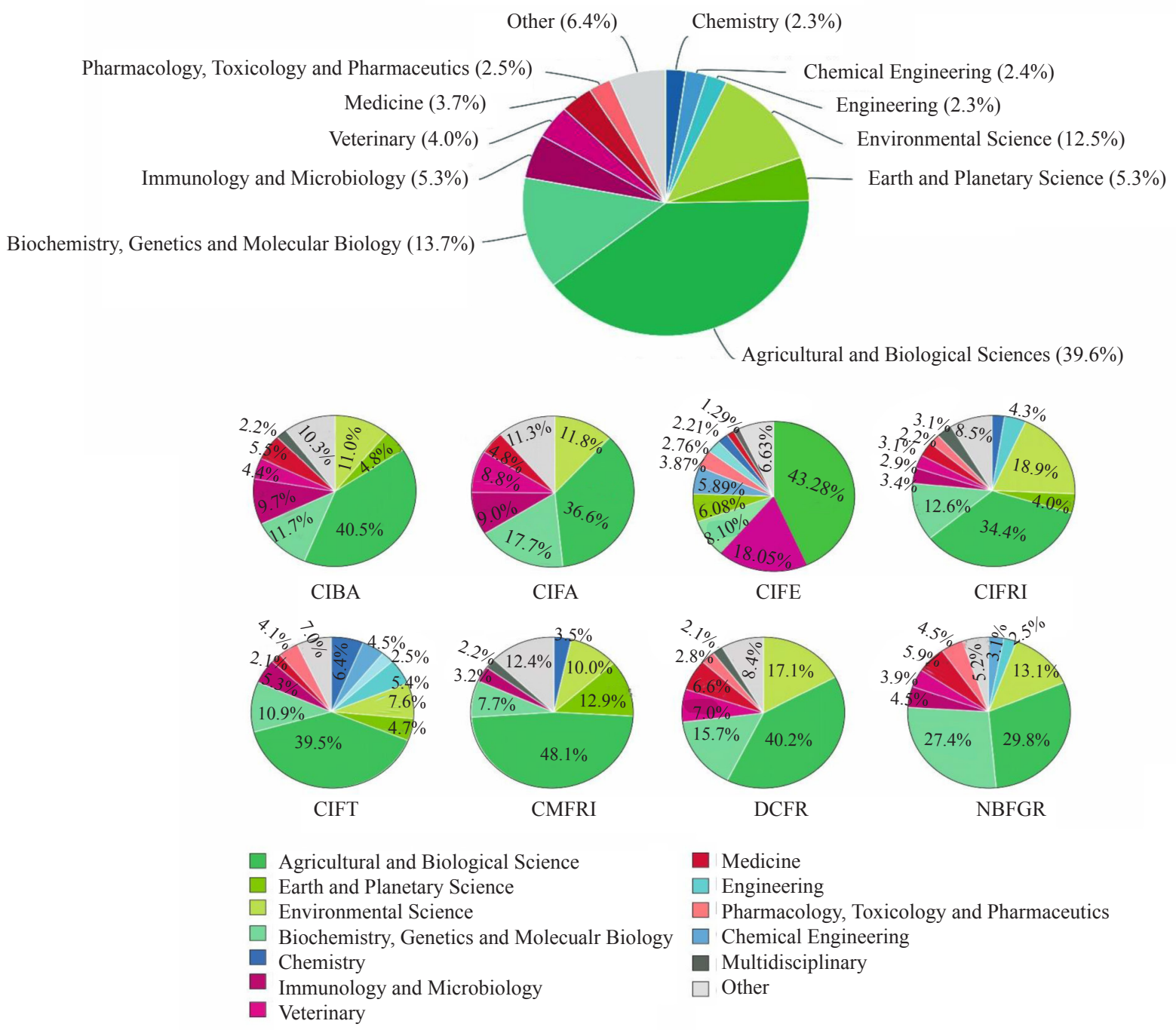

Fig. 6. Subject area-wise publication details of Fisheries Research Institutes under ICAR during 2009-2018 


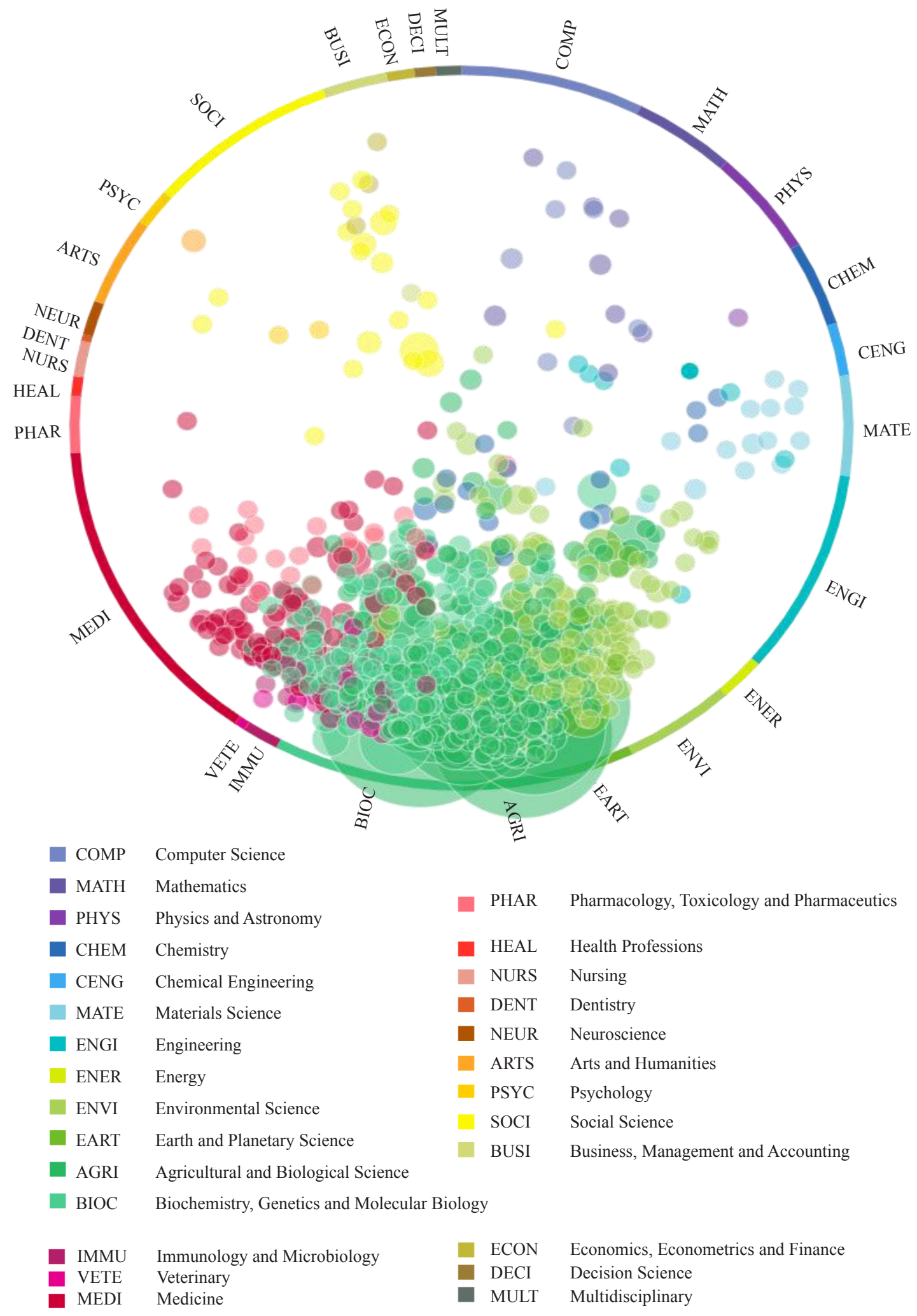

Fig. 7. 'Topic prominence analysis' based on scholarly output (top 500 topic clusters) of ICAR Fisheries Research Institutes 
'Graphene, Carbon Nanotubes, Nanotubes'; 'Catalysis, Synthesis (Chemical), Catalysts'; 'Catalysts, Zeolites, Hydrogenation' and 'T-Lymphocytes, Neoplasms, Immunotherapy' were the top five clusters with research momentum, high visibility and scope for future funding. The ranking of these topics based on prominence in science is helpful for the research managers to identify those topics that reveal supply and demand in the science systems (Klavens and Boyack et al., 2017; Munoz-Ecija et al., 2019).

\section{Top key-phrases of scholarly outputs}

The key-phrase based assessment of publications indicates the current focus of a particular research domain (Rehn et al., 2014). The 'SciVal' extracts top key-phrases through text mining by 'Elsevier Fingerprint Engine' in titles and abstracts of the documents (SciVal, 2020). The 'key-phrase' cloud shown in Fig. 8 indicates that the predominant key-phrase appeared in the research papers of ICAR fisheries institutes during 2009-18 was 'India' (reference value: 1), followed by 'Labeo rohita', 'fish', 'shrimp', 'coast' and 'fishery'. The key-phrase denoted in green colour indicates the increase of key phrase occurrence in publications, while the key-phrase in blue colour indicates the decrease in occurrence frequency during the assessment years (2009-18). The decrease in frequency of key-phrases such as 'Penaeus monodon', 'Clarias batrachus', 'catfishes', 'Cirrhinus cirrohosa' and 'Macrobrachium rosenbergii' and increase in the frequency of key-phrases viz., 'Pangasionodon hypophthalmus' and 'Litopenaeus vannamei' clearly indicated the increasing research focus from indigenous species to exotic farmed species in India. This could be attributed to the fact that the latter two species are widely cultivated commercially and constitute a significant portion of the cultivated area and thus driving the research focus towards them.
The production of $P$. monodon has reduced drastically since 2009, especially after the introduction of $P$. (=L.) vannamei, which explains the shift in the research focus of ICAR fisheries laboratories on the latter (Srinivas et al., 2016). It is noteworthy that the cultivation of $P$. (=L.) vannamei has been perceived to be more advantageous due to the fact that they can be grown in the widely varying environment in freshwater to brackishwater and the production and export economics are much higher. Likewise, annual production of up to 1 million $\mathrm{t}$ has been predicted by the year 2025 for P. hypophthalmus (Mohan et al., 2019), a status attained only by Indian major carps, so far.

\section{Top journals in Indian fisheries research}

The journal which published most (408 papers; $12.5 \%$ ) of the research papers from the ICAR fisheries institutes during the assessment period was the Indian Journal of Fisheries (IJF), which is published by ICAR, New Delhi. A recent scientometric study report on South Asian fisheries and aquaculture concluded IJF as the top journal with a high article count (Bandara and Wijewardene, 2018). The diagrammatic representation of bibliometrics of the top 10 journals which account for $31.84 \%$ (1039 papers) of the total papers is depicted in Fig. 9. There were 4 international journals listed under the top 10 journals, which published about 320 papers during the study period. It is also worth mentioning here that the citation impact of the publications of those journals, i.e., Aquaculture, Aquaculture Research and Fish and Shellfish Immunology was observed to be significantly higher than the other journals. These results are in accordance with other scientometric research performed during the contemporary period on Indian fisheries research (Chaman et al., 2016; Vinitha et al., 2018; Bhoomaiah

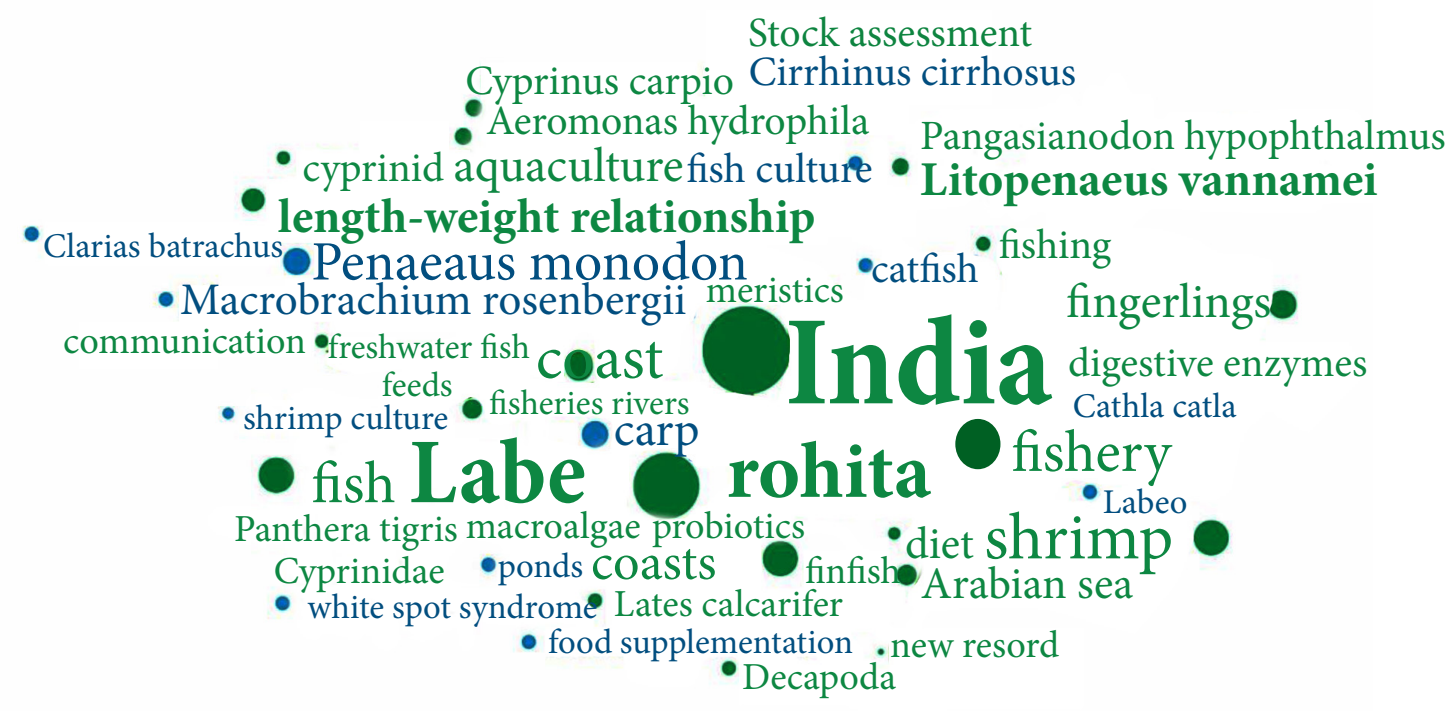

Fig. 8. A cloud view of 'Key-phrases’ used in ICAR tisheries research publications during 2009-18 
et al., 2020). The shift in the choice of impactful international journals by the researchers in national fisheries research institutions in comparison to the earlier study (Jayashree and Arunachalam, 2000), wherein the top 10 journals comprised only of Indian journals, indicates the improvement in the research quality of ICAR fisheries institutes over the years.

The SciVal-based scientometric assessment of research outputs of ICAR fisheries research institutes shows a steady growth in scientific publications during 2009-18. The high FWCI value for publications and the increase in the proportion of publications in top journals and citation percentiles in recent years indicate improvement in the quality of research over the study period. However, this study suggests the need and scope for further improvement in research publications, productivity i.e., publications per scientist, especially in the case of larger institutes. The topic prominence analysis suggest the areas that have high research momentum and scope for future funding in national fisheries laboratories, though they do not necessarily represent the importance of research, which are driven by strategic goals and societal values of the respective national fisheries research institutes. While significant research focus towards potential commercially cultivable species, i.e., $P$. (=L.) vannamei and $P$. hypophthalmus could well be justified based on their extent of cultivation and commercial significance, there is a need to undertake strategic research on indigenous fish genetic resources to ensure sustainable growth and development of the Indian fisheries sector. Detailed analysis on variations in the subject area-wise productivity between domain-specific research institutes and academic as well as research institutes and various drivers like budgetary allocations and demographic attributes of the researchers, would provide a deeper understanding of the research productivity of the institutions and would aid in identification of parameters which could be addressed to improve the research output.

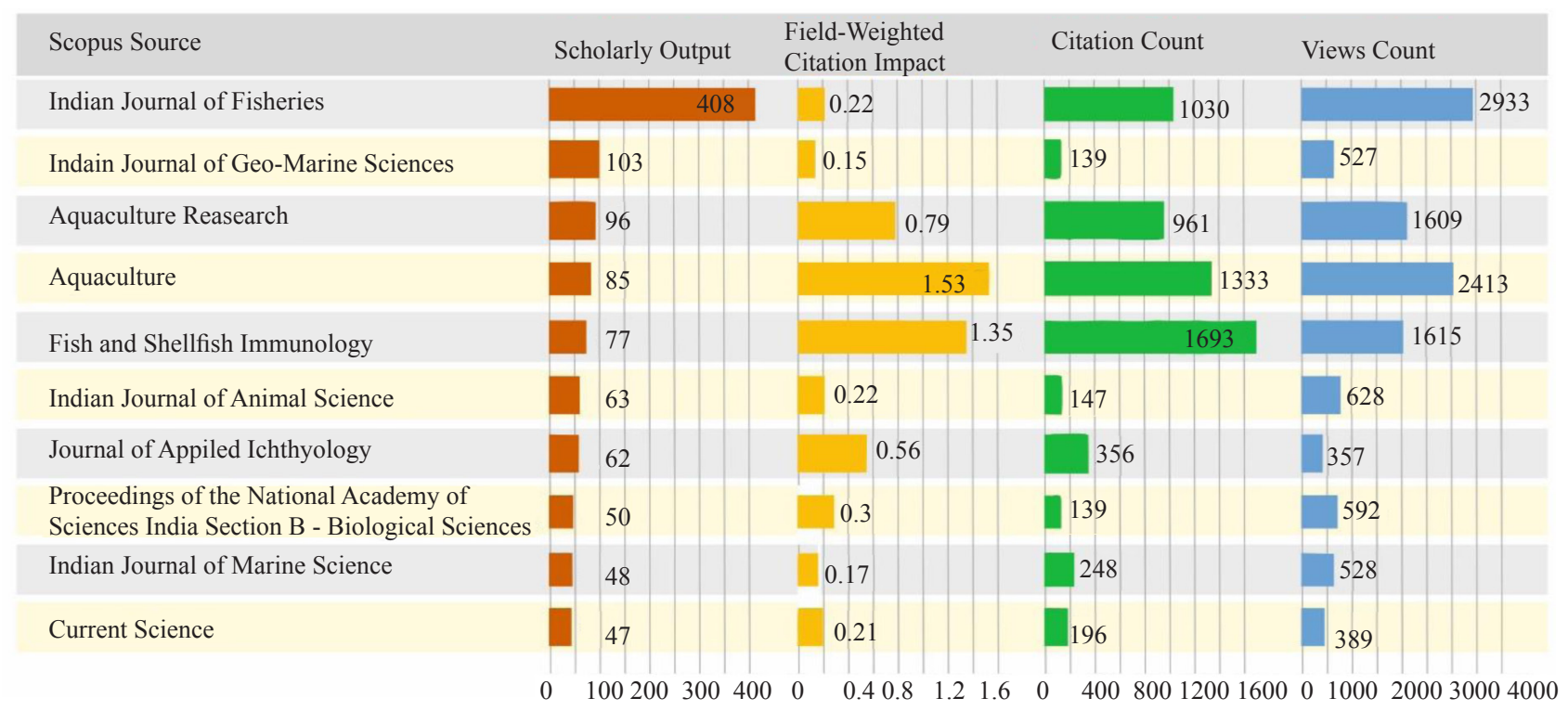

Fig. 9. Top 10 journals for ICAR Indian Fisheries Research Institutes during 2009-18.

[Note: 'Indian Journal of Marine Sciences' is renamed as 'Indian Journal of Geo-Marine Sciences']

\section{Supplementary Information}

Table S1. Institute-wise research output from different fisheries research institutions under ICAR during 2009-18

\begin{tabular}{llll}
\hline Name of the Institute & $\begin{array}{l}\text { No. of research } \\
\text { publications }\end{array}$ & Citation Count & $\begin{array}{l}\text { Field-Weighted Citation Impact } \\
\text { (FWCI) }\end{array}$ \\
\hline ICAR-Central Marine Fisheries Research Institute, Kochi & 847 & 4500 & 0.46 \\
ICAR-Central Institute of Fisheries Education, Mumbai & 825 & 6716 & 0.64 \\
ICAR-National Bureau of Fish Genetic Resources, Lucknow & 487 & 4047 & 0.52 \\
ICAR-Central Institute of Freshwater Aquaculture, Bhubaneswar & 483 & 4696 & 0.61 \\
ICAR-Central Institute Brackishwater Aquaculture, Chennai & 350 & 2786 & 0.73 \\
ICAR-Central Institute of Fisheries Technology, Kochi & 308 & 2602 & 0.57 \\
ICAR-Central Inland Fisheries Research Institute, Barrackpore & 284 & 1957 & 0.58 \\
ICAR-Directorate of Coldwater Fisheries Research, Bhimtal & 178 & 1121 & 0.47 \\
\hline
\end{tabular}


Table S2. Prominent topic clusters ( $>95$ Percentile value) identified in SciVal based on ICAR-Fisheries Institutes scholarly output (top 500 topic cluster)

\begin{tabular}{|c|c|}
\hline Topic Cluster & Prominence Percentile \\
\hline Photocatalysis; Photocatalysts; Solar Cells & 99.933 \\
\hline Graphene; Carbon Nanotubes; Nanotubes & 99.866 \\
\hline Catalysis; Synthesis (Chemical); Catalysts & 99.799 \\
\hline Catalysts; Zeolites; Hydrogenation & 99.732 \\
\hline T-Lymphocytes; Neoplasms; Immunotherapy & 99.665 \\
\hline Plasmons; Metamaterials; Surface Plasmon Resonance & 99.531 \\
\hline MicroRNAs; Long Untranslated RNA; Neoplasms & 99.398 \\
\hline Microbial Fuel Cells; Anaerobic Digestion; Bioreactors & 99.063 \\
\hline Climate Models; Model; Rainfall & 98.929 \\
\hline Arabidopsis; Plants; Genes & 98.862 \\
\hline Ozonization; Degradation; Wastewater Treatment & 98.728 \\
\hline Metagenome; Probiotics; Bacteria & 98.661 \\
\hline Electricity; Energy; Economics & 98.594 \\
\hline Dengue; Viruses; Dengue Virus & 98.327 \\
\hline Anti-Bacterial Agents; Infection; Methicillin-Resistant Staphylococcus aureus & 98.26 \\
\hline Cellulose; Lignin; Cellulases & 98.126 \\
\hline Soil; Biochar; Soil Organic Carbon & 98.059 \\
\hline Mesenchymal Stromal Cells; Stem Cells; Induced Pluripotent Stem Cells & 97.657 \\
\hline Aerosols; Air Quality; Atmospheric Aerosols & 97.59 \\
\hline Pharmaceutical Preparations; Nanoparticles; Tablets & 97.39 \\
\hline Industry; Innovation; Entrepreneurship & 97.256 \\
\hline Adsorption; Adsorbents; Activated Carbon & 97.189 \\
\hline Chromatin; Histones; Epigenomics & 96.653 \\
\hline Oceans; Lakes; Dissolved Organic Matter & 95.984 \\
\hline Microfluidics; Fluidic Devices; Microchannels & 95.917 \\
\hline Polypropylenes; Lactic Acid; Blending & 95.649 \\
\hline Supply Chains; Supply Chain Management; Industry & 95.382 \\
\hline RNA; Ribosomes; Proteins & 95.315 \\
\hline Remote Sensing; Image Classification; Satellite Imagery & 95.114 \\
\hline
\end{tabular}

\section{Acknowledgements}

The authors thank Dr. J. K. Jena, Deputy Director General (Fisheries), ICAR, New Delhi, Dr. R. Soundararajan, Senior Scientific Consultant, National Centre for Sustainable Coastal Management (NCSCM), and Dr. T. Balaguru, Consultant, ICAR-NAARM for reviewing the manuscript and offering critical inputs on the manuscript. The study was undertaken as part of inhouse projects funded by ICAR, New Delhi, India.

\section{References}

Aksnes, D. W. 2003. A macro study of self-citation. Scientometrics, 56: 235-246.

Arunachalam, S. and Balaji, J. 2001. Fish science research in China: How does it compare with fish research in India? Scientometrics, 52(1): 13-28. DOI: 10.1023/A:101274282 6813.

ASRB 2009. Revised Career Advancement Scheme. Agricultural Scientists Recruitment Board, New Delhi, India. http:// asrb.org.in/images/asrb/pdfs/cas-guidelines-1-1-2009.pdf. (Accessed 09 November 2020).

Ayyappan, S. and Diwan, A. D. 2006. Fisheries research and development in India. Fishing Chimes, 26(1): 19-23.
Bandara, T. and Wijewardene, L. N. 2018. Scientific footprint of South Asian fisheries and aquaculture research: A scientometric study between 2000 and 2017. International Symposium on Emerging Trends in Education and Library and Information Science-LibSym 2018. 09-10 August 2018. Eastern University, Sri Lanka. http://www.digital.lib.esn.ac.lk /handle/123456789/3774. (Accessed 18 November 2020).

Bhoomaiah, D., Krishnan, P., Kantharajan, G., Sangeeta, B. and Rajendran, K. V. 2020. A scientometric assessment of research on white spot syndrome virus (WSSV) in India vis-a-vis the world (1998-2017). Aquaculture, 520: 734672. https://doi.org/10.1016/j.aquaculture.2019.734672.

Bornmann, L. and Leydesdorff, L. 2014. Scientometrics in a changing research landscape: Bibliometrics has become an integral part of research quality evaluation and has been changing the practice of research. EMBO Reports, 15(12): 1228-1232. doi: 10.15252/embr.201439608.

Brennan, N. 2018. Research analytics tools - An overview. EIFL General Assembly, 06-08 November 2018. National Library of Qatar, Doha. https://www.eifl.net/sites/default/ files/resources/201808/niamheifl2research_analytics_ tools.pdf. (Accessed 28 September 2020).

Chaman, S. M., Dharani Kumar, P. and Biradar, B. S. 2016 Scientometric study of the research performance on fishery: The Indian perspective. J. Adv. Lib. Inf. Sci., 5(2): 337-341. 
Dresbeck, R. 2015. SciVal. J. Med. Libr. Ass., 103(3): 164.

Elsevier 2020b. Topic prominence in science. https://www. elsevier.com/solutions/scival/releases/topic-prominencein-science. (Accessed 11 November 2020)

Elsevier 2020a. What is Field-weighted Citation Impact (FWCI)? https://service.elsevier.com/app/answersdetail/a_id/1 4894/supporthub/scopus/ /what-is-field-weighted-citationimpact-\%28fwci\%29\%3F/. (Accessed 30 September 2020)

Esfe, M. H., Wongwises, S., Asadi, A., Karimipour, A. and Akbari, M. 2015. Mandatory and self-citation; types, reasons, their benefits and disadvantages. Sci. Eng. Ethics, 21(6): 1581-1585. doi: 10.1007/s11948-014-9598-9.

Hyland, K. 2003. Self-citation and self-reference: Credibility and promotion in academic publication, J. Am. Soc. Inf. Sci. Technol., 54(3): 251-259. https://doi.org/10.1002/asi.10204.

Jayashree, B. and Arunachalam, S. 2000. Mapping fish research in India. Curr. Sci., 79(5): 613-620.

Khor, K. A. and Yu, L. 2016. Influence of international coauthorship on the research citation impact of young universities. Scientometrics, 107: 1095-1110. https://doi. org/10.1007/s11192-016-1905-6.

Klavans, R. and Boyack, K. W. 2017. Research portfolio analysis and topic prominence. J. Informetr., 11(4): 1158-1174. https://doi.org/10.1016/j.joi.2017.10.002.

Kumaresan, R., Ezhilrani, R., Vinitha, K. and Jayaraman, R. 2014. Indian research contributions in the Aquaculture journal during 1972-2011: A scientometric study. Libr. Philos. Pract., 1185.

Kumaresan, R., Ezhilrani, R., Vinitha, K., Sivaraman, P. and Jayaraman, R. 2014. Research trends in fish stock assessment during 1999-2013: A scientometrics study. Int. J. Lib. Inf. Sci., 3(2): 24-36.

Kumaresan, R., Vinitha, K. and Kannan, K. 2015. Scientometric analysis of seaweed research with reference to Web of Science. Libr. Philos. Pract., 1348.

Lawani, S. 1982. On the heterogeneity and classification of author self-citations. J. Am. Soc. Inf. Sci., 33: 281-284. https://doi.org/10.1002/asi.4630330506.

Mohan, A. B., Gopala Rao, K. Ch. and Ravi Babu, G. 2019. Recent trends in Pangasius Pangasianodon hypophthalmus farming, production and marketing in India. AsianPacific Aquaculture 2019, 19-21 June 2019, Chennai, Tamil Nadu, India. World Aquaculture Society, AsianPacific Chapter. https://www.was.org/Meeting/Program/ PaperDetail/154045 (Accessed 09 November 2020).

Munoz-Ecija,T.,Vargas-Quesada, B. and ChinchillaRodriguez, Z. 2019. Coping with methods for delineating emerging fields: Nanoscience and nanotechnology as a case study. J. Informetr., 13(4): 100976. https://doi.org/10.1016/j.joi. 2019.100976.

$\mathrm{OECD}$, n. d. Enhancing research performance through evaluation, impact assessment and priority setting. Organisation for Economic Cooperation and Development
(OECD). https://www.oecd.org/sti/inno/Enhancing-PublicResearch-Performance.pdf (Accessed 27 September 2020).

Pinto,A.P., Mejdalani, G., Mounce, R., Silveira, L. F., Marinoni, L. and Rafael, J. A (Pre-print). Are publications on zoological taxonomy under attack?. SciELO - Scientific Electronic Library Online, Sao Paulo, Brazil. https://doi.org/10.1590/ SciELOPreprints.1164.

Purkayastha, A., Palmaro, E., Falk-Krzesinski, H. J. and Baas, J. 2019. Comparison of two article-level, field-independent citation metrics: Field-Weighted Citation Impact (FWCI) and Relative Citation Ratio (RCR). J. Informetr., 13(2): 635-642.

Rajan, K. S., Swaminathan, S. and Vaidhyasubramaniam, S. 2018. Research output of Indian institutions during 20112016: Quality and quantity perspective, Curr. Sci., 114(4): 740-746. DOI: 10.18520/cs/v114/i04/740-746.

Rehn, C., Kronman, U., Gornitzki, C., Larsson, A. and Wadskog, D. 2014. Bibliometric handbook for Karolinska Institutet, Karolinska Institutet, Huddinge.

Silas, E. G. 2003. History and development of fisheries research In India, J. Bombay Nat. Hist. Soc., 100(2\&3): 502-520.

SciVal 2020. SciVal. https://www.elsevier.com/solutions/scival? dgcid=RN_AGCM_Sourced_300005487. (Accessed 18 May 2020).

Singh, N., Datta, S. N. and Handa, T. S. 2019. Research dynamics in Indian fisheries and aquaculture: A scientometric analysis. Curr. Sci., 117(3): 382.

Smith, S. 2017. An introduction to bibliometrics and citation analysis. https://www.aber.ac.uk/en/media/ departmental/ informationservices/pdf/intro-bibliometrics1711.pdf. (Accessed 28 September 2020).

Soares, J. A., Bresciani, K., Ramos, T., De Matos, L., Castellane, P. and Cerdeira, M. 2015. A review of the state of the art of self-citations. J. Educ. Soc. Policy, 2: 75-79.

Srinivas, D., Venkatrayulu, C. and Swapna, B. 2016 Sustainability of exotic shrimp Litopenaeus vannamei (Boone, 1931) farming in coastal Andhra Pradesh, India: Problems and Issues. Eur. J. Exp. Biol., 6(3): 80-85.

UC 2020. Measure Impact: Field normalised impact metrics: The Field-Weighted Citation Impact. University of Canterbury, New Zealand. https://canterbury.libguides. com/impactmeasure. (Accessed 11 November 2020).

Vinitha, K., Kumaresan, R. and Kannan, K. 2018. Twenty-five years of fisheries research in India based on Web of Science. Proceedings of the International Conference on Exploring the horizons of Library and Information Sciences: From Libraries to knowledge hub. Indian Statistical Institute, Bangalore, India.

Vivekanandan, E., Manjusha, U. and Remya, R. 2009. Analysis of research papers published in the Journal of Marine Biological Association of India during 1959-2008. Mar. Biol. Ass. India, 51(1): 14-20.

Waltman, L. 2016. A review of the literature on citation impact indicators. J. Informetr., 10(2): 365-391.

Date of Receipt $\quad: 19.11 .2020$

Date of Acceptance : 19.12.2020 